\title{
Effects of combined supplementation with EPA and vitamin $E$ on the inflammatory response and oxidative capacity of male basketball players
}

\author{
A. Djazayery, R. Ghiasvand, M. Djalali, M. Hosseini and S. A. Keshavarz \\ School of Public Health, Tehran University of Medical Sciences, Tehran, Iran
}

The objective of the present study was to investigate the effects of vitamin E and EPA supplementation on the blood levels of proinflammatory cytokine $\mathrm{TNF} \alpha$, anti-inflammatory cytokine IL-2 and the erythrocyte antioxidant enzyme glutathione reductase (GR) in male basketball players.

In a randomized double-blind placebo-controlled clinical trial thirty-six healthy well-trained male basketball players (17-35 years old) were randomized into four groups to take daily $2 \mathrm{~g}$ EPA (plusEPA ${ }^{\mathrm{TM}}$; Minami Nutrition, Edegem, Belgium), $400 \mathrm{mg}$ vitamin E, a combination of the two or a placebo. Venous blood samples for analysis were taken from the subjects between 17.00 and 18.00 hours after exercising for $2 \mathrm{~h}$ and at the beginning and after 6 weeks of supplementation. Serum IL-2 and TNF $\alpha$ were measured with Bender Medsystems kits (Vienna, Austria) using ELISA and GR was determined by the Sauberlich method ${ }^{(1)}$.

The Table shows that for the EPA + vitamin E group when compared with the vitamin E, EPA and placebo groups there was a decrease in the serum TNF $\alpha$ level $(P<0.005$; paired $t$ test $)$ and an increase in the serum IL-2 level $(P<0.05)$. The erythrocyte GR level increased significantly in both the EPA + vitamin E $(P=0.04)$ and vitamin E groups $(P=0.01)$.

\begin{tabular}{|c|c|c|c|c|c|c|c|c|c|c|c|c|c|c|c|c|}
\hline \multirow[t]{3}{*}{ Group.. } & \multicolumn{4}{|c|}{1} & \multicolumn{4}{|c|}{2} & \multicolumn{4}{|c|}{3} & \multicolumn{4}{|c|}{4} \\
\hline & \multicolumn{2}{|c|}{$\begin{array}{c}\text { Initial } \\
\end{array}$} & \multicolumn{2}{|c|}{ Final } & \multicolumn{2}{|c|}{$\begin{array}{c}\text { Initial } \\
\end{array}$} & \multicolumn{2}{|c|}{ Final } & \multicolumn{2}{|c|}{$\begin{array}{c}\text { Initial } \\
\end{array}$} & \multicolumn{2}{|c|}{ Final } & \multicolumn{2}{|c|}{ Initial } & \multicolumn{2}{|c|}{ Final } \\
\hline & Mean & $\overline{\mathrm{SD}}$ & Mean & $\mathrm{SD}$ & Mean & $\overline{\mathrm{SD}}$ & Mean & $\overline{\mathrm{SD}}$ & Mean & $\overline{\mathrm{SD}}$ & Mean & $\overline{\mathrm{SD}}$ & Mean & $\overline{\mathrm{SD}}$ & Mean & SD \\
\hline IL-2 (pg/ml) & 18.9 & 9.2 & $25.1 *$ & 13.3 & 19.1 & 8.7 & 28.9 & 2.9 & 20.7 & 12.1 & 26.1 & 1.3 & 31.5 & 2.1 & 33.4 & 5 \\
\hline $\mathrm{TNF} \alpha(\mathrm{pg} / \mathrm{ml})$ & 10.9 & 6 & $7.4 * * *$ & 4.3 & 10.4 & 5.0 & 6.1 & 0.9 & 7.8 & 2.6 & 4.2 & 1.4 & 8.7 & 5.1 & 7.6 & 0.4 \\
\hline $\mathrm{GR}(\mathrm{U} / \mathrm{ml})$ & 2.9 & 1.4 & $3.9^{* *}$ & 1.7 & 3.4 & 1.4 & 4.8 & 0.6 & 2.0 & 1.9 & $5.4 \dagger$ & 1.5 & 3.9 & 1.5 & 4.1 & 0.2 \\
\hline
\end{tabular}

Group 1, EPA + vitamin E; group 2, EPA; group 3, vitamin E; group 4, placebo.

Mean values were significantly different from the initial value: $* P=0.05, * * P=0.04, * * * P=0.005, \dagger P=0.01$.

Adding EPA to vitamin E supplements can result in desirable changes in the inflammatory response and antioxidant capacity of male basketball players. This effect would have implications from a practical point of view, since exercise produces inflammatory and oxidative effects.

1. Sauberlich HE, Judd JH Jr, Nichoalds GE, Broquist HP \& Darby WJ (1972) Am J Clin Nutr 25, 756-762. 